Обзорная статья/Review article

УДК 664.63

DOI: http://doi.org/10.20914/2310-1202-2019-1-232-237

Конструктивные и технологические приемы интенсификации замеса теста и повышения качества хлеба

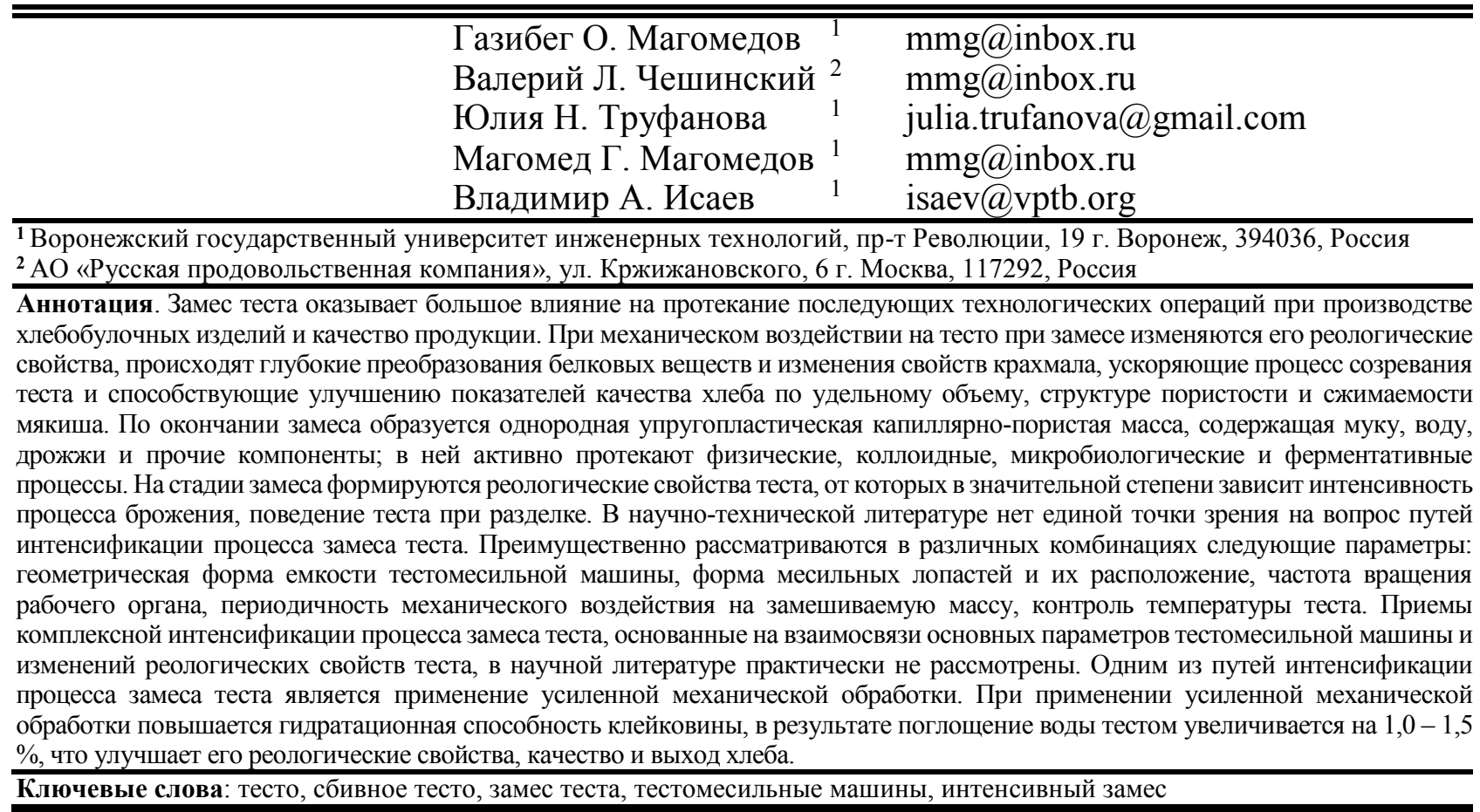

\title{
Constructive and technological methods of intensification of kneading and improving the quality of bread
}

\begin{tabular}{llll}
\hline \hline Gazibeg O. Magomedov & 1 & mmg@inbox.ru \\
Valery L. Cheshinsky & 2 & mmg@inbox.ru \\
Julia N. Trufanova & 1 & julia.trufanova@gmail.com \\
Magomed G. Magomedov & 1 & mmg@inbox.ru \\
Vladimir A. Isaev & 1 & isaev@ vptb.org \\
\hline
\end{tabular}

\footnotetext{
${ }^{1}$ Voronezh state university of engineering technologies, Revolution Av., 19 Voronezh, 394036, Russia
}

2 JSC Russian food company, Krzhizhanovskogo str., 6, Moscow, 117292, Russia

Abstract. Kneading dough has a great influence on the processing of subsequent technological operations of the bakery production and products quality. The rheological properties change by mechanical action on the dough during kneading, and deep transformations of protein substances and changes in the properties of starch occurred. These changes cause accelerating the process of dough maturation and improvement of the bread quality in terms of specific volume, porosity structure and compressibility of the crumb. At the end of the dough kneading, a homogeneous elastoplastic capillary-porous mass containing flour, water, yeast and other components is formed and physical, colloidal, microbiological and enzymatic processes actively proceed in it. At the kneading stage, rheological properties of the dough are formed, on which the intensity of the fermentation process, the behavior of the dough during cutting depends. In the scientific and technical literature, there is absent the common point of view on the question about ways to intensify the process of dough kneading. The following parameters are mainly considered in various combinations: the geometric shape of the kneading machine capacity, the shape of the kneading blades and their location, the speed of the working body, the frequency of mechanical action on the kneading mass, the control of the test temperature. Methods of the complex intensification of the kneading process, based on the relationship of the main kneading machine parameters and changes in the rheological properties of the dough, are practically not considered in the scientific literature. One of the ways to intensify the process of dough kneading is the using of reinforced machining treatment. In the application of reinforced mechanical treatment the hydration capacity of the gluten increases, as a result, the water absorption by dough is increased by 1.0 to $1.5 \%$, which improves its rheological properties, quality and yield of bread. Keywords: dough, whipped pastry, dough mixers, heavy kneading

Для цитирования

Магомедов Г.О., Чешинский В.Л., Труфанова Ю.Н., Магомедов М.Г., Исаев В.А. Конструктивные и технологические приемы интенсификации замеса теста и повышения качества хлеба // Вестник ВГУИТ. 2019. тТ. 81. № 1. С. 232-237. doi:10.20914/2310-1202-2019-1-232-237

232
For citation

Magomedov G.O., Cheshinsky V.L., Trufanova Ju.N., Magomedov M.G., Isaev V.A. Constructive and technological methods of intensification of kneading and improving the quality of bread. Vestnik VGUIT [Proceedings of VSUET]. 2019. vol. 81. no. 1. pp. 232-237. (in Russian). doi:10.20914/2310-1202-2019-1-232-237 


\section{Введение}

Замес теста оказывает большое влияние на протекание последующих технологических операций при производстве хлебобулочных изделий и качество продукции. При механическом воздействии на тесто при замесе изменяются его реологические свойства, происходят глубокие преобразования белковых веществ и изменения свойств крахмала, ускоряющие процесс созревания теста и способствующие улучшению показателей качества хлеба по удельному объему, структуре пористости и сжимаемости мякиша $[1,2]$.

По окончании замеса образуется однородная упругопластическая капиллярно-пористая масса, содержащая муку, воду, дрожжи и прочие компоненты; в ней активно протекают физические, коллоидные, микробиологические и ферментативные процессы. На стадии замеса формируются реологические свойства теста, от которых в значительной степени зависит интенсивность процесса брожения, поведение теста при разделке [3].

Замес пшеничного теста отличается от ржаного и является более сложным. В пшеничной муке содержится 7-26\% белковых веществ, которые в основном определяют физические и хлебопекарные свойства теста, а также качество выпеченного хлеба. В пшеничном тесте образуется губчатый, упругий клейковинный каркас, тесто становится эластичным и упругим. Для ржаного теста характерны высокая вязкость, пластичность, слабые упругость и растяжимость. Наибольшее влияние механическая проработка при замесе оказывает на качество пшеничного теста $[1,3]$.

При классическом проведении замеса можно выделить три характерные стадии: 1 - механическое смешивание и аэрация, в результате которых достигается равномерное распределение компонентов по всей массе; 2 - гидролитическое воздействие влаги на сухие компоненты смеси, сопровождающееся когезией; 3 - структуррообразование, заключающееся в формировании белкового каркаса теста, который в дальнейшем определяет его газо- и формоудерживающую способность. На скорость и характер течения отдельных стадий процесса влияют свойства муки, рецептурные добавки (жир, сахар, окислители и др.), специфика механического воздействия месильных органов, интенсивность и длительность замеса, обусловленные конструкцией машины [4-7].

Замес теста осуществляется в тестомесильных машинах различных конструкций в течение 1-20 мин в зависимости от интенсивности механического воздействия. Для получения высококачественного теста замес необходимо осуществлять при оптимальных интенсивности, длительности, температуре и частоте воздействия месильной лопасти.

Интенсивность замеса определяется удельной работой, затраченной на замес 1 г теста. На эту величину непосредственно влияет и длительность замеса.

По интенсивности воздействия рабочего органа на обрабатываемую массу тестомесильные машины делятся на три группы:

- обычные тихоходные - рабочий процесс не сопровождается заметным нагревом теста, удельный расход энергии 5-12 Дж/г;

- быстроходные (машины для интенсивного замеса теста) - рабочий процесс сопровождается нагревом теста на 5-7 ${ }^{\circ} \mathrm{C}$, удельный расход энергии 15-30 Дж/г;

- супербыстроходные (суперинтенсивные) - замес сопровождается нагревом теста на $10-20{ }^{\circ} \mathrm{C}$, что требует устройства водяного охлаждения корпуса месильной камеры, либо предварительного охлаждения воды, используемой для замеса теста, удельный расход энергии 30-45 Дж/г [5].

Цель работы - исследование влияния технологических факторов и конструктивных особенностей тестомесильных машин на повышение интенсивности процесса замеса теста и качества хлебобулочных изделий; определение дальнейших путей их совершенствования.

\section{Обсуждение}

Величина удельной работы является ориентировочной и не имеет строго разделенного ряда, поскольку может на одной и той же машине изменяться в зависимости от длительности замеса, определяемой качеством муки [5].

В научно-технической литературе нет единой точки зрения по вопросу путей интенсификации процесса замеса теста. Преимущественно рассматриваются в различных комбинациях следующие параметры: геометрическая форма емкости тестомесильной машины, форма месильных лопастей и их расположение, частота вращения рабочего органа, периодичность механического воздействия на замешиваемую массу, контроль температуры теста [4-12]. Приемы комплексной интенсификации процесса замеса теста, основанные на взаимосвязи основных параметров тестомесильной машины и изменений реологических свойств теста, в научной литературе практически не рассмотрены.

Одним из путей интенсификации процесса замеса теста является применение усиленной механической обработки. Такое тесто по окончании процесса брожения имеет более упругие свойства по сравнению с тестом без обработки, 
и процесс его разжижения затормаживается, вероятно, из-за частичного восстановления структуры $[1,3]$. Значительная роль в этом явлении отводится окислительно-восстановительным процессам с участием кислорода воздуха, механически захваченного тестом в процессе замеса. Так, при окислении - SH-групп глиадина и глютенина происходит образование дополнительных дисульфидных связей и, как следствие, упрочнение структуры белка, а окисление - SH-групп протеолитических ферментов и их активаторов приводит к снижению степени протеолиза белков в тесте. В результате повышается его вязкость и упругость [1-3].

При применении усиленной механической обработки повышается гидратационная способность клейковины, в результате поглощение воды тестом увеличивается на 1,0-1,5\%, что улучшает его реологические свойства, качество и выход хлеба [3].

При интенсивном замесе тесто осветляется по сравнению с тестом, полученным при обычном замесе, из-за аэрации его составных частей включения кислорода воздуха в массу теста и участия его в окислении около 31\% пигментов муки - ксантофилловых, каротиноидных и хлорофилловых [1-3].

Физико-химические свойства крахмальных зерен при интенсивном замесе также изменяются: повышается их атакуемость амилазами муки, увеличивается доля водорастворимых углеводов и восстанавливающих сахаров. Газообразующая и газоудерживающая способность теста, замешенного с усиленной механической обработкой, улучшается, и эта тенденция сохраняется в тестовой заготовке в период расстойки $[1,3,8,11]$.

В ряде работ показано, что при замесе в результате частичного перехода механической энергии в тепловую температура теста повышается. Чрезмерный перегрев теста может привести к ухудшению его структурно-механических свойств, нарушению технологического режима. В связи с этим в конструкциях быстроходных тестомесильных машин необходимо предусматривать емкости, снабженные водяной рубашкой для охлаждения теста [6, 8-11].

Общее повышение удельного расхода энергии, вызывающее интенсификацию процесса замеса и созревания теста и повышение его качества, нельзя считать объективным технологическим критерием. Интенсивность замеса характеризуется количеством работы, расходуемой на единицу рабочего времени, на которую влияют одновременно интенсивность и длительность замеса, а интенсивность, в свою очередь, зависит от частоты вращения месильной лопасти и механизма ее воздействия на тесто, т. е. конструкции тестомесильной машины. Следовательно, при одной и той же интенсивности можно получить различную удельную работу путем изменения длительности замеса. При этом важно определить оптимальный расход энергии, так как тесто становится более растяжимым и менее упругим при излишней механической обработке [5, 11]. Разработчики чорливудского способа производства хлеба считают, что для качества готовых изделий лучше, если одна и та же работа при замесе теста совершается с более высокой скоростью $[12,13]$.

Количество энергии, передаваемой тесту во время замеса, также зависит от геометрической формы дежи и лопасти месильного органа. Для интенсификации процесса передачи механической энергии тесту в конструкциях тестомесильных машин предусматривают неподвижную штангу или перегородку, двойной месильный орган.

Оптимальное значение удельной работы при замесе теста зависит от множества факторов: вида, сорта и свойств муки, влажности теста, рецептуры (дозировки соли, сахара, жировых продуктов и др.), применения улучшителей окислительно-восстановительного действия и др.

Различные способы интенсификации процесса замеса теста и результаты работ по совершенствованию конструкций тестомесильных машин рассмотрены в многочисленных публикациях отечественных и зарубежных ученых [12-19].

Для интенсификации процесса замеса теста N. Larsen предложено увеличение мощности электродвигателей и площади рабочих органов тестомесильной машины [20].

Разработана конструкция тестомесильной машины с вертикально расположенным по центру цилиндрической дежи рабочим органом, представляющим собой полый вращающийся вал, на котором равномерно установлены три пары месильных лопастей различной длины, размещенных под углом $60^{\circ}$ относительно друг друга. Так как тестомесильные лопасти выполнены полыми, то по внутренней поверхности вала в них поступают жидкие компоненты, которые через отверстия в лопастях равномерно распределяются по всему объему дежи. Данная конструкция рабочего органа тестомесильной машины позволяет интенсифицировать процесс замеса, сократить его длительность и повысить производительность [21].

Для снижения энергозатрат и улучшения качества теста предложена конструкция тестомесильной машины периодического действия с объемно-винтовым рабочим органом. В результате придания замешиваемой массе 
дополнительного вертикального перемещения достигается непрерывное перемещение массы теста по всему объему месильной емкости за счет создания разноскоростных потоков движения замешиваемой массы одновременно в горизонтальной и вертикальной плоскостях. Предлагаемая конструкция рабочего органа тестомесильной машины позволяет интенсифицировать процесс замеса теста, повысить производительность и снизить энергозатраты [22, 23].

Разработан способ, предусматривающий подачу замешенного теста в аэратор для насыщения его сжатым воздухом. Данный прием позволяет интенсифицировать процесс замеса, добиться равномерного распределения компонентов, повысить качество готовых изделий с увеличенным сроком годности [24].

Наиболее перспективным способом является механический способ разрыхления структуры теста под избыточным давлением воздуха, который позволяет резко сократить длительность технологического процесса, повысить качество и выход готовых хлебобулочных изделий, увеличить срок их годности. Это достигается благодаря одновременной реализации двух физических факторов: интенсивности замеса теста и высокой скорости растворения в нем газа $[3,14,25]$.

Предложен способ приготовления бездрожжевого теста и конструкция тестомеса. Механическое разрыхление теста производится за счет перемешивания рецептурных компонентов с газированной водой в герметизированной емкости при избыточном давлении диоксида углерода 0,4 - 0,5 МПа. Данный способ позволяет повысить качество диетических хлебобулочных изделий, расширить ассортимент бездрожжевых изделий, интенсифицировать технологический процесс и снизить потребность в производственных площадях [26].

Разработана конструкция месильносбивальной машины с герметичной месильной камерой, оборудованной двухконтурной водяной рубашкой, установленной под углом $60^{\circ}$

\section{ЛИТЕРАТУРА}

1 Ауэрман Л.Я. Технология хлебопекарного производства: учеб.; 9-е изд., перераб. и доп.; под общ. ред. Л.И. Пучковой. СПб.: Профессия, 2005. 416 с.

2 Пащенко Л.П. Физико-химические основы технологии хлебобулочных изделий: учеб. пособие. Воронеж, 2006. $311 \mathrm{c}$.

3 Пучкова Л.И., Поландова Р.Д., Матвеева И.В Технология хлеба, кондитерских и макаронных изделий. Ч. 1. Технология хлеба. СПб.: ГИОРД, 2005. 557 с.

4 Хромеенков В.М. Технологическое оборудование хлебозаводов и макаронных фабрик. СПб.: ГИОРД, 2008. $480 \mathrm{c}$.

5 Лисовенко А.Т., Литовченко И.Н., Зирнис И.В. и др. Смесительные машины в хлебопекарной и кондитерской промышленности; под ред. А.Т. Лисовенко. К.: Урожай, 1990. 192 с. к горизонту. Месильный орган выполнен в виде рамной мешалки, закрепленной на валу, состоящей из четырех скоб, расположенных под углом $90^{\circ}$ относительно друг друга. Скорость вращения рабочего органа 8,3-13,3 c-1. Месильносбивальная машина снабжена компрессором и ресивером. В месильную камеру подается сжатый воздух под давлением 0,4 МПа. Предлагаемая конструкция позволяет повысить качество бездрожжевого хлеба за счет более эффективного перемешивания, интенсифицировать процесс замеса теста, снизить энергозатраты, сократить потребность в производственных площадях, увеличить выход хлеба [27].

Предложена конструкция месильносбивальной машины, включающая месильную камеру с крышкой, месильный орган с электродвигателем, устройство для выгрузки готового продукта, компрессор и ресивер. Месильная камера выполнена герметичной и снабжена рубашкой охлаждения. При этом нижняя часть камеры выполнена в форме полусферы и в ее верхней части проходит вал с насаженным на него месильным органом. Месильный орган установлен горизонтально с минимальным зазором относительно днища и представляет собой четыре полукольца, расположенных под углом 90 относительно друг друга. В крышку месильной камеры вмонтирован золотник для сброса избыточного давления, месильная камера сообщается с компрессором и ресивером. Такая конструкция месильно-сбивальной машины позволяет интенсифицировать процесс перемешивания рецептурных компонентов, повысить качество сбивного бездрожжевого теста и снизить энергозатраты на его приготовление [28].

\section{Заключение}

Анализ существующих тестомесильных машин и способов замеса теста показал, что необходимо дальнейшее совершенствование конструкции тестомесильных машин в направлении обеспечения высокоинтенсивного воздействия на структуру теста в среде сжатых газов.

6 Магомедов Г.О., Пономарева Е.И., Рыжов В.В. Влияние формы месильной лопасти на энергетические характеристики сбивания и качество бездрожжевого полуфабриката // Хлебопродукты. 2011. № 10. С. 48-49.

7 Байрамов Э.Э. Анализ эффективности работы и основных критериев выбора тестомесильных машин// Austrian Journal of Technical and Natural Sciences. 2014. № 7-8. C. 72-76.

8 Литовченко И.Н., Сидоренко С.И., Клементенко В.Л., Лисовенко А.Т. Воздействие интенсивного замеса на длительность брожения полуфабрикатов и качество хлеба // Хлебопекарная и кондитерская промышленность. 1984. № 11. C. 23-24.

9 Верболоз Е.И., Антуфьев В.Т., Савченко Р.Н. Совершенствование технологии и оборудования для интенсификации производства мучных кондитерских изделий // Научный журнал НИУ ИТМО. Серия: Процессы и аппараты пищевых производств. 2015. № 3(25). С. 58-63. 
10 Литовченко И.Н., Лисовенко А.Т. Определение расхода энергии на нагрев при замесе теста // Хлебопекарная и кондитерская промышленность. 1983. № 8. С. 28-29.

11 Литовченко И.Н. Интенсификация процесса замеса и совершенствование тестомесильных машин периодического действия. Киев, 1984. 213 с.

12 Cauvain S.P., Young L.S. et al. Technology of Breadmaking; 2nd edn. New York: Springer Science + Business Media, 2007. 397 p.

13 Cauvain S.P., Young L.S. The Chorleywood Bread Process. Cambrige: Woodhead Publishing Ltd., 2006. 192 p.

14 Магомедов Г.О., Пономарева Е.И. Научные и практические основы технологии сбивных функциональных хлебобулочных изделий. Воронеж: ВГТА, 2010. 241 с.

15 Мацкевич И.В. Совершенствование технологического процесса производства теста для хлебобулочных изделий. Красноярск, 2016. 122 с.

16 Федотьин И.М. Физико-математические основы интенсификации процессов и аппаратов пищевой и химической технологии; под. ред. А.А. Доменского. Кишинёв: Штиница, 1987. 262 с.

17 Boularias A. Predictive representations for sequential decision making under uncertainty. 2010.

18 Faubion J.M., Dresse P.C., Diehl K.C. Dynamic Theological testing of wheat flour doughs. St. Paul: MN, 1985. P. 91-116.

19 Alava J.M., Millar S.J., Salmon S.E. The Determination of Wheat Breadmaking Performance and Bread Dough Mixing Time by NIR Spectroscopy for High Speed Mixers // Journal of Cereal Science. 2001. V. 33 (1). P. 71-81. 20 Larsen N., Halgh K., Wilson A., Higgins P. Comparison of industrial and laboratory dough mixers and development. 2004. 57 p.

21 Пат. № 2475027, RU, A21C 1/02. Тестомесильная машина / Самойлов В.А., Ярум А.И.; заявитель и патентообладатель ФГОУ ВПО «Красноярский государственный аграрный университет». № 2011136498/13; Заявл. 01.09.2011; Опубл. 20.02.2013, Бюлл. № 5.

22 Мацкевич И.В., Невзоров В.Н., Братилова Н.П. Определение технологических параметров тестомесильной машины с объемно-винтовым рабочим органом // Вестник КрасГАУ. 2015. № 1. С. 76-81.

23 Пат. № 2571907, RU, A21C1/02. Тестомесильное устройство / Мацкевич И.В., Невзоров В.Н., Холопов В.Н.; заявитель и патентообладатель ФГБОУ ВПО «Красноярский государственный аграрный университет»; № 2014125969/13; Заявл. 26.06.2014; Опубл. 27.12.2015., Бюлл. № 36.

24 Пат. № 2376766, RU, A21D 8/02, 13/08. Способ замеса теста / Акульчев C.Н.; заявитель и патентообладатель Общество с ограниченной ответственностью «Акульчев». № 2008114104/13; Заявл. 09.04.2008; Опубл. 27.12.2009, Бюлл. № 36 .

25 Магомедов Г.О., Крутских С.Н., Косинов В.Н., Рыжов В.В. Разработка рациональной конструкции сбивальной машины для приготовления хлебопекарного теста механическим способом разрыхления в промышленных условиях // Вестник Воронежской Государственной Технологической Академии. 2011. № 3. С. 86-88.

26 Пат. № 2454865, RU, A21D 8/02, A21C 1/00. Способ приготовления бездрожжевого теста для выпечки хлебобулочных изделий и тестомес для его осуществления / Арсланов Т.А, Меджидов 3.М. № 2010151252/13; Заявл. 13.12.2010; Опубл. 10.07.2012, Бюлл. № 19.

27 Пат. № 2462036, RU, A21C 1/00. Месильносбивальная машина / Магомедов Г.О., Рыжов В.В., Крутских С.Н., Косинов В.Н.; заявитель и патентообладатель ГОУ ВПО «Воронежская государственная технологическая академия». № 2011111075/13; Заявл. 23.03.2011; Опубл. 27.09.2012, Бюлл. № 27.
28. Пат. № 2457681, RU, A21C 1/06. Месильносбивальная машина / Магомедов Г.О., Рыжов В.В., Крутских С.Н., Косинов В.Н., Пономарева Е.И.; заявитель и патентообладатель ГОУ ВПО «Воронежская государственная технологическая академия». № 2010143952/12; Заявл. 26.10.2010; Опубл. 10.05.2012, Бюлл. № 22.

\section{REFERENCES}

1 Auerman L.Ya. Tekhnologiya khlebopekarnogo proizvodstva [Technology of baking production]. St. Petersburg, Professiya, 2005. 416 p. (in Russian).

2 Pashchenko L.P. Fiziko-khimicheskiye osnovy tekhnologii khlebobulochnykh izdeliy [Physical and chemical bases of technology of bakery products]. Voronezh, 2006. 311 p. (in Russian).

3 Puchkova L.I., Polandova R.D., Matveeva I.V. Tekhnologiya khleba, konditerskikh i makaronnykh izdeliy. Chast' 1. Tekhnologiya khleba [Technology of bread, confectionery and pasta. Part 1 . The technology of bread]. St. Petersburg, GIORD, 2005. 557 p. (in Russian).

4 Hromenkov V.M. Tekhnologicheskoye oborudovaniye khlebozavodov i makaronnykh fabrik [Technological equipment bakeries and pasta factories]. St. Petersburg, GIORD, 2008. 480 p. (in Russian).

5 Lisovenko A.T., Litovchenko I.N., Zirnis V.I. et al. Smesitel'nyye mashiny $\mathrm{v}$ khlebopekarnoy i konditerskoy promyshlennosti [The mixing machines in the bakery and confectionery industry]. Urozhay, 1990. 192 p. (in Russian).

6 Magomedov G.O., Ponomareva E.I., Ryzhov V.V. The influence of the kneading blade shape on the energy characteristics of the churning and the quality of the yeastfree semi-finished product. Khleboprodukty [Bakery products]. 2011. no. 10. pp. 48-49. (in Russian).

7 Bayramov E.E. Analysis of the efficiency and the main criteria for the selection of kneading machines. Austrian journal of technical and natural sciences. 2014. no. 7-8. pp. 72-76. (in Russian).

8 Litovchenko I.N., Sidorenko S.I., Clementina V.L., Lisovenko A.T. The effect of intensive mixing on the duration of fermentation of semi-finished products and the quality of bread. Khlebopekarnaya $i$ konditerskaya promyshlennost' [Bakery and confectionery industry]. 1984. no. 11. pp. 23-24. (in Russian).

9 Verboloz E.I., Antufiev V.T., Savchenko R.N. Improvement of technology and equipment for intensification of production of flour confectionery products. Nauchnyy zhurnal NIU ITMO. Seriya: Protsessy $i$ apparaty pishchevykh proizvodstv [Scientific journal ITMO. Series: processes and apparatus of food production]. 2015. no. 3 (25). pp. 58-63. (in Russian).

10 Litovchenko I.N., Lisovenko A.T. Determination of energy consumption for heating when kneading dough. Khlebopekarnaya i konditerskaya promyshlennost' [Bakery and confectionery industry]. 1983. no. 8. pp. 28-29. (in Russian).

11 Litovchenko I.N. Intensifikatsiya protsessa zamesa i sovershenstvovaniye testomesil'nykh mashin periodicheskogo deystviya [Intensification of the kneading process and improvement of dough mixing machines of periodic action]. Kiev, 1984. 213 p. (in Russian).

12 Cauvain S.P., Young L.S. et al. Technology of Breadmaking; 2nd edn. New York, Springer Science + Business Media, 2007. 397 p.

13 Cauvain S.P., Young L.S. The Chorleywood Bread Process. Cambrige, Woodhead Publishing Ltd., 2006. 192 p. 
14 Magomedov G.O., Ponomareva E.I. Nauchnyye i prakticheskiye osnovy tekhnologii sbivnykh funktsional'nykh khlebobulochnykh izdeliy [Scientific and practical bases of technology of whipped functional bakery products]. Voronezh, VSTA, 2010. 241 p. (in Russian).

15 Matskevich I.V. Sovershenstvovaniye tekhnologicheskogo protsessa proizvodstva testa dlya khlebobulochnykh izdeliy [Improvement of technological process of dough production for bakery products]. Krasnoyarsk, 2016. 122 p. (in Russian).

16 Fedot'in I.M. Fiziko-matematicheskiye osnovy intensifikatsii protsessov i apparatov pishchevoy i khimicheskoy tekhnologii [Physical and mathematical bases of intensification of processes and devices of food and chemical technology]. Kishinev, Stinitsa, 1987. 262 p. (in Russian).

17 Boularias A. Predictive representations for sequential decision making under uncertainty. 2010.

18 Faubion J.M., Dresse P.C., Diehl K.C. Dynamic Theological testing of wheat flour doughs. St. Paul, MN, 1985. pp. 91-116.

19 Alava J.M., Millar S.J., Salmon S.E. The Determination of Wheat Breadmaking Performance and Bread Dough Mixing Time by NIR Spectroscopy for High Speed Mixers. Journal of Cereal Science. 2001. vol. 33 (1). pp. 71-81.

20 Larsen N., Halgh K., Wilson A., Higgins P. Comparison of industrial and laboratory dough mixers and development. 2004. $57 \mathrm{p}$.

21 Samoilov V.A., Yarum A.I. Testomesil'naya mashina [Kneading machine]. Patent RF, no. 2475027, 2013.

\section{СВЕДЕНИЯ ОБ АВТОРАХ}

Газибег О. Магомедов д.т.н., профессор, кафедра технологии хлебопекарного, кондитерского, макаронного и зерноперерабатывающего производств, Воронежский государственный университет инженерных технологий, пр-т Революции, 19, г. Воронеж, 394036, Россия, mmg@inbox.ru

Валерий Л. Чешинский к.т.н., председатель совета директоров, АО «Русская продовольственная компания», ул. Кржижановского, 6, г. Москва, 117292, Россия, mmg@inbox.ru

Юлия Н. Труфанова к.т.н., доцент, кафедра технологии хлебопекарного, кондитерского, макаронного и зерноперерабатывающего производств, Воронежский государственный университет инженерных технологий, пр-т Революции, 19, г. Воронеж, 394036, Россия, julia.trufanova@gmail.com

Магомед Г. Магомедов д.т.н., профессор, кафедра технологии хлебопекарного, кондитерского, макаронного и зерноперерабатывающего производств, Воронежский государственный университет инженерных технологий, пр-т Революции, 19, г. Воронеж, 394036, Россия, mmg@inbox.ru

Владимир А. Исаев аспирант, кафедра технологии хлебопекарного, кондитерского, макаронного и зерноперерабатывающего производств, Воронежский государственный университет инженерных технологий, пр-т Революции, 19, г. Воронеж, 394036, Россия, isaev@vptb.org

\section{КРИТЕРИЙ АВТОРСТВА}

Все авторы в равной степени принимали участие в написании рукописи и несут ответственность за плагиат

КОНФЛИКТ ИНТЕРЕСОВ

Авторы заявляют об отсутствии конфликта интересов.

ПОСТУПИЛА 27.01.2019

ПРИНЯТА В ПЕЧАТЬ 18.02.2019
22 Matskevich I.V., Nevzorov V.N., Bratilova N.P. Determination of technological parameters of kneading machine with volumetric-screw working body. Vestnik KrasGAU [Herald KrasSAU]. 2015. no. 1. pp. 76-81. (in Russian).

23 Matskevich I.V., Nevzorov V.N., Slaves V.N. Testomesil'noye ustroystvo [A mixer device]. Patent RF, no. $2571907,2015$.

24 Akulchev S.N. Sposob zamesa testa [Method of kneading dough]. Patent RF, no. 2376766, 2009.

25 Magomedov G.O., Krutskikh S.N., Kosinov V.N., Ryzhov V.V. Development of a rational design compactors \& chocolate melting machine for making bakery pastry mechanically loosening in industrial conditions. Vestnik Voronezhskoy Gosudarstvennoy Tekhnologicheskoy Akademii [Herald Of The Voronezh State Technological Academy]. 2011. no. 3. pp. 86-88. (in Russian).

26 Arslanov T.A, Medzhidov Z.M. Sposob prigotovleniya bezdrozhzhevogo testa dlya vypechki khlebobulochnykh izdeliy $i$ testomes dlya yego osushchestvleniya [Method of preparation of non-yeasted dough for baking bakery products and dough mixer for its implementation]. Patent RF, no. 2454865, 2012.

27 Magomedov G.O., Ryzhov V.V., Krutskikh S.N., Kosinov V.N. Mesil'no-sbival'naya mashina [Kneading machine]. Patent RF, no. 2462036, 2012.

28 Magomedov G.O., Ryzhov V.V., Krutskikh S.N., Kosinov V.N., Ponomareva E.I. Mesil'no-sbival'naya mashina [Kneading machine]. Patent RF, no. 2457681, 2012.

\section{INFORMATION ABOUT AUTHORS}

Gazibeg O. Magomedov Dr. Sci. (Engin.), professor, bakery technology, confectionery, pasta and grain processing industries department, Voronezh state University of engineering technologies, Revolution Av., 19 Voronezh, 394036, Russia, mmg@inbox.ru

Valery L. Cheshinsky Cand. Sci. (Engin.), chairman of the board, JSC "Russian food company", Krzhizhanovsky str., 6 Moscow, 117292, Russia, mmg@inbox.ru

Julia N. Trufanova Cand. Sci. (Engin.), associate professor, bakery technology, confectionery, pasta and grain processing industries department, Voronezh state University of engineering technologies, Revolution Av., 19 Voronezh, 394036, Russia, julia.trufanova@gmail.com

Magomed G. Magomedov Dr. Sci. (Engin.), professor, bakery technology, confectionery, pasta and grain processing industries department, Voronezh state University of engineering technologies, Revolution Av., 19 Voronezh, 394036, Russia, mmg@inbox.ru

Vladimir A. Isaev graduate student, bakery technology, confectionery, pasta and grain processing industries department, Voronezh state University of engineering technologies, Revolution Av., 19 Voronezh, 394036, Russia, isaev@vptb.org

\section{CONTRIBUTION}

All authors equally participated in the writing of the manuscript and are responsible for plagiarism

\section{CONFLICT OF INTEREST}

The authors declare no conflict of interest.

RECEIVED 1.27.2019

ACCEPTED 2.18.2019 